\title{
Optimal Nonlinear Taxation of Income and Education Expenditures
}

\author{
Jang-Ting Guo* \\ University of California, Riverside \\ Alan Krause ${ }^{\dagger}$ \\ University of York
}

26 August 2010

\begin{abstract}
Despite using a variety of models and assumptions, the existing literature has overwhelmingly concluded that education policy should be regressive. In this paper, we examine a two-period model in which the government may impose nonlinear taxes on both labour income and education expenditures. Individuals undertake education in the first period to increase their second-period wages. Our main result is that optimal education policy in our model is progressive. Specifically, if the government can commit, it is optimal for high-skill individuals to face a zero marginal tax rate on their education expenditures, while that for low-skill individuals is negative. If the government cannot commit, the optimal marginal tax rate on education expenditures by high-skill individuals is positive, while that for low-skill individuals remains negative.
\end{abstract}

Keywords: education policy; dynamic nonlinear taxation; commitment.

JEL Classifications: H21, H24.

*Department of Economics, 4123 Sproul Hall, University of California, Riverside, CA, 92521, U.S.A., Phone: 1-951-827-1588, Fax: 1-951-827-5685, E-mail: guojt@ucr.edu.

${ }^{\dagger}$ Corresponding Author. Department of Economics and Related Studies, University of York, Heslington, York, YO10 5DD, U.K., Phone: 44-(0)1904-433-572, Fax: 44-(0)1904-433-759, E-mail: ak519@york.ac.uk. 


\section{Introduction}

A fundamental question in public economics is how government policy might improve upon the allocation achieved by the free market, which tends to be efficient but unfair. To a large extent, this question has been addressed using the Mirrlees [1971] and Stiglitz [1982] models of nonlinear income taxation. In the Mirrlees/Stiglitz model, inequality arises from differences in individuals' skill levels, which results in differences in their income-earning abilities. However, the government cannot implement (the first-best) personalised lump-sum taxation based on skill levels as the Second Welfare Theorem would recommend, owing to the assumption that each individual's skill level is private information. Instead, the government is constrained to use (the second-best) incentivecompatible nonlinear income taxation, in which optimal taxation involves some efficiency loss due to the necessity of inducing marginal distortions to achieve redistribution.

The nonlinear income taxation literature typically assumes that skill levels are fixed. In reality though, skill levels can change over time, in particular by individuals investing in education. This observation immediately suggests that education policy may play an important role alongside income taxation policy, and a large literature has arisen exploring their relationship (reviewed below). Despite using different models and making a variety of assumptions, the literature has overwhelmingly concluded that education should be subsidised and/or education policy should be regressive. ${ }^{1}$ That is, policy should seek to encourage higher-skill individuals to acquire education relatively more than lower-skill individuals.

In this paper, we revisit optimal income taxation and education policy, but with two key features together that distinguish our analysis from the existing literature: (i) the government may impose nonlinear taxation on both labour income and education expenditures, ${ }^{2}$ and (ii) our model is dynamic, and we consider the possibility that the government cannot commit to its future tax policy. Specifically, in the two-period model

\footnotetext{
${ }^{1}$ It is worth noting that public provision of education can be equivalent to subsidising private investments in education. Also, a uniform education subsidy is often regressive in its effect, since higher-skill individuals tend to acquire more education than lower-skill individuals.

${ }^{2}$ For convenience, we will continue to refer to the taxation of income and education, where it is understood that a negative tax is a subsidy.
} 
that we employ, ${ }^{3}$ the government may take advantage of skill-type information revealed in period 1 to implement lump-sum taxes in period 2. We allow the government to impose nonlinear taxes on education expenditures because the usual argument made against nonlinear taxation of commodities, based on the possibility of retrade opportunities, is weak for the case of education as it is not easily retradable. Therefore, restricting attention to linear taxation of education expenditures would seem difficult to justify. We consider a multi-period model because the education process is intrinsically dynamic, i.e., current investments in education lead to higher skills and wages in the future. Dynamic models of taxation raise the issue of whether the government can commit to its future tax policy. We consider optimal taxation with and without commitment, because an argument can be made for each case. ${ }^{4}$

Our main result is that optimal education policy in our model is progressive. When the government can commit, low-skill individuals have their education levels distorted upwards via a negative marginal tax rate, while high-skill individuals' education levels are undistorted, i.e., they face a zero marginal tax rate on their education expenditures. Distorting the low-skill type's education upwards facilitates redistribution by increasing their second-period wage, but may also undermine redistribution by creating an incentive for high-skill individuals to mimic, i.e., pretend to be low skill. However, because lowskill individuals work longer than mimicking high-skill individuals do, the benefits of distorting the low-skill type's education upwards outweigh the costs. This argument also helps justify a negative marginal tax rate on education expenditures by low-skill individuals when the government cannot commit, but now there is an additional force working in its favour. Under lump-sum taxation in period 2, an individual's utility is decreasing in their wage rate. Thus distorting the low-skill type's education upwards decreases their second-period utility, and correspondingly increases that of high-skill individuals. This facilitates redistributive income taxation by making mimicking less

\footnotetext{
${ }^{3}$ Since the optimal nonlinear income tax problem without commitment is most easily solved by backwards induction, we use a finite-horizon model.

${ }^{4}$ One could argue in favour of the commitment assumption on the basis that real-world tax systems are not frequently redesigned. Gaube [2007], for example, makes this argument. On the other hand, the commitment assumption has been criticised as being unrealistic, since the present government cannot easily impose binding constraints on the tax policies of future governments.
} 
attractive. Likewise, it is optimal to impose a positive marginal tax rate on education expenditures by high-skill individuals, since this increases their second-period utility and decreases that of low-skill individuals. This again makes redistributive income taxation more effective by making mimicking less attractive. Optimal education policy in our model is therefore progressive, because it involves the low-skill type's education being distorted upwards and, if the government cannot commit, the high-skill type's education being distorted downwards.

The remainder of the paper is organised as follows. Section 2 reviews the related literature, while Section 3 outlines the analytical framework that we consider. Section 4 examines optimal taxation with commitment, while Section 5 examines optimal taxation without commitment. Section 6 contains some concluding comments, while proofs are relegated to an appendix.

\section{$2 \quad$ Related Literature}

The literature on the relationship between education policy and optimal income taxation is quite extensive. An early study by Ulph [1977] examines how the government should distribute a given amount of education resources amongst a population of individuals who differ in their skill levels, when the government can also use redistributive income taxation. He concludes that education policy should be regressive, in that higherskill individuals should receive more education than lower-skill individuals. Hare and Ulph [1979] examine education policy when education may be provided publicly or privately. They find that public provision is desirable when the government cannot implement lump-sum taxes, but is constrained instead to use (distortionary) income taxation. Grout [1983] also examines public versus private provision of education. He concludes that previous arguments made against a free market in education are overstated once imperfect information on part of the government is taken into account.

Tuomala [1986] and Brett and Weymark [2003] investigate how individuals' educational choices affect the design of an optimal nonlinear income tax system. They find that some standard results, such as the optimality of zero marginal tax rates at the 
endpoints of the tax schedule, may no longer hold. Boadway, et al. [1996] argue that education should be subsidised to offset underinvestment in education by individuals, which arises if the government cannot commit to a future redistributive tax system. That is, education subsidies can alleviate the "hold-up" problem associated with investments in education. Andersson and Konrad [2003] show that the argument for education subsidies based on the hold-up problem is weakened if individuals are internationally mobile. Krause [2009a] also examines a model in which individuals can be internationally mobile, but concludes that optimal education policy is ambiguous in that it can be optimal to distort education levels upwards, downwards, or not at all.

Fleurbaey, et al. [2002] examine education policy in a model in which each individual's cost of acquiring education is private information. They show that an increase in the government's aversion to inequality, as reflected in the social welfare function, leads to more inequality in educational achievements even though education policy per se is progressive. De Fraja [2002] examines a model in which households are distinguished by their incomes and the abilities of their children. Households therefore differ in both their ability to pay for education and their ability to benefit from education. In this setting, De Fraja [2002] shows that the optimal education policy is regressive.

Bovenberg and Jacobs [2005] argue that education subsidies and redistributive taxation are "Siamese twins", in that education subsidies offset the distortions created by redistributive income taxation. Krause [2006] examines redistributive taxation and education policy in a model in which education is skill specific, with low-skill individuals benefiting from vocational training and high-skill individuals benefiting from professional education. He shows that it is optimal to distort professional education upwards or vocational training downwards relative to their first-best levels. The paper most closely related to ours is that by Maldonado [2008]. Maldonado examines a static model (as does most of the literature), but like us he allows the government to impose nonlinear taxes on labour income and education expenditures. He shows that high-skill individuals should face a zero marginal tax rate on their education expenditures, while the sign of the optimal marginal tax rate applicable to education expenditures by low-skill individuals is generally ambiguous. Blumkin and Sadka [2008] show, contrary to most of the 
literature, that a case can be made for taxing education. Starting with an optimal linear or nonlinear income tax system, they show that introducing a small tax on education is desirable provided the correlation between innate skill and learning ability is high enough, and the social welfare function is sufficiently egalitarian.

As our model is dynamic, our paper is also related to the "new dynamic public finance" literature which extends the static Mirrlees [1971] nonlinear income tax model to a dynamic setting. Surveys of this literature are provided by Golosov, et al. [2006, 2010], while a textbook treatment is provided by Kocherlakota [2010]. For the most part, this literature has assumed that the government can commit to its future tax policy, i.e., the government cannot use skill-type information revealed in earlier periods to redesign the tax system and achieve a better allocation in latter periods. Models of dynamic nonlinear income taxation without commitment that are similar to the one we employ have been used by Apps and Rees [2006], Brett and Weymark [2008], Krause [2009b], and Guo and Krause [2010], among others. However, none of these papers examine education policy.

\section{Analytical Framework}

There is a unit measure of individuals in the economy who live for two periods, with a proportion $\phi \in(0,1)$ being high-skill workers and the remaining $(1-\phi)$ being lowskill workers. First-period wages are fixed and are denoted by $w_{i}^{1}$, where $i \in\{H, L\}$ represents the high-skill and low-skill types, respectively. Second-period wages depend in part on education and are denoted by $w_{i}^{2}=w_{i}^{1}+\alpha e_{i}$, where $\alpha>0$ and $e_{i}$ is the amount of education acquired by a type $i$ individual in period 1 . The assumption that second-period wages are a linear function of education is made for simplicity, but also because there does not seem to be any a priori reason to assume that $\partial w_{i}^{2}(\cdot) / \partial e_{i}$ differs by type if individuals undertake education appropriate to their needs. For example, it seems reasonable to expect that low-skill individuals will undertake training in, say, basic mathematics, which would increase their skills considerably but be of little benefit to high-skill individuals (who would already have these skills). Similarly, high-skill 
individuals would benefit from additional training in, say, computer programming, but such training would be inaccessible to low-skill individuals. Accordingly, there does not seem to be any particular reason to assume that $\partial w_{i}^{2}(\cdot) / \partial e_{i}$ is greater for one type of individual than the other. ${ }^{5}$ It is also assumed that $w_{H}^{1}>w_{L}^{1}$ and $w_{H}^{2}>w_{L}^{2}$ for all relevant levels of education, which simplifies the analysis considerably by ruling out the possibility of skill reversals.

In period 1, individuals spend their non-leisure time working to support themselves and acquiring education to increase their second-period wage. Both types of individual have the same preferences, which are represented by the utility function $u\left(c_{i}^{1}\right)-v\left(l_{i}^{1}\right)-$ $z\left(e_{i}\right)$, where $c_{i}^{1}$ and $l_{i}^{1}$ represent type $i$ 's first-period consumption and labour supply, respectively. The function $u(\cdot)$ is increasing and strictly concave, while $v(\cdot)$ and $z(\cdot)$ are increasing and strictly convex. ${ }^{6}$ Since period 2 is the last period, no one acquires education in period 2. Second-period utility is therefore $u\left(c_{i}^{2}\right)-v\left(l_{i}^{2}\right)$, where $c_{i}^{2}$ and $l_{i}^{2}$ represent type $i$ 's second-period consumption and labour, respectively. Finally, type $i$ 's pre-tax income in period $t$ is equal to $y_{i}^{t}=w_{i}^{t} l_{i}^{t}$, and for simplicity we assume that there are no savings.

It is assumed that the government can impose nonlinear taxation on both income and education expenditures. In order to derive expressions for the marginal tax rates applicable to income and education, suppose individuals face smooth nonlinear income tax functions $T^{t}\left(y_{i}^{t}\right)$ in periods 1 and 2 , as well as a smooth nonlinear education tax function $\tau\left(e_{i}\right)$ in period 1. Each individual would then solve the following programme:

$$
\max _{c_{i}^{1}, l_{i}^{1}, e_{i}, c_{i}^{2}, l_{i}^{2}} u\left(c_{i}^{1}\right)-v\left(l_{i}^{1}\right)-z\left(e_{i}\right)+\delta\left[u\left(c_{i}^{2}\right)-v\left(l_{i}^{2}\right)\right]
$$

subject to:

$$
c_{i}^{1}+e_{i} \leq y_{i}^{1}-T^{1}\left(y_{i}^{1}\right)-\tau\left(e_{i}\right)
$$

\footnotetext{
${ }^{5}$ Nevertheless, in the concluding section we discuss the implications of relaxing this assumption.

${ }^{6} \mathrm{By}$ assuming that $z(\cdot)$ is increasing and strictly convex, we are implicitly assuming that there is disutility in acquiring education in much the same way as there is disutility in working. It would make no difference to our results if instead utility was assumed to be increasing in education acquired, say due to the existence of non-pecuniary benefits from education.
} 


$$
c_{i}^{2} \leq y_{i}^{2}-T^{2}\left(y_{i}^{2}\right)
$$

where (3.1) is lifetime utility, (3.2) and (3.3) are first- and second-period budget constraints, respectively, and $\delta \in(0,1]$ is the discount factor.

It is shown in the Appendix that the solution to programme (3.1) - (3.3) yields the following expressions for the marginal tax rates:

$$
\begin{gathered}
\operatorname{MTR}_{i}^{t}:=\frac{\partial T^{t}(\cdot)}{\partial y_{i}^{t}}=1-\frac{v^{\prime}\left(l_{i}^{t}\right)}{u^{\prime}\left(c_{i}^{t}\right) w_{i}^{t}} \\
\operatorname{MTRE}_{i}:=\frac{\partial \tau(\cdot)}{\partial e_{i}}=\frac{\alpha \delta l_{i}^{2} v^{\prime}\left(l_{i}^{2}\right)}{u^{\prime}\left(c_{i}^{1}\right) w_{i}^{2}}-\frac{z^{\prime}\left(e_{i}\right)}{u^{\prime}\left(c_{i}^{1}\right)}-1
\end{gathered}
$$

where $M T R I_{i}^{t}$ is the marginal income tax rate faced by type $i$ individuals in period $t$, and $M T R E_{i}$ is the marginal tax rate applicable to education expenditures by type $i$ individuals in period 1. Equation (3.4) is the same as the expression obtained in static models that the marginal income tax rate is equal to one minus the marginal rate of substitution of pre-tax income for consumption (see, e.g., Stiglitz [1982]). Equation (3.5) is the expression for the marginal tax rate on education. The first term on the righthand side of (3.5) represents the marginal benefit of an additional unit of education, obtained via higher second-period wages, divided by the marginal utility of first-period consumption. The second term on the right-hand side of (3.5) represents the marginal cost of an additional unit of education, which reflects the effort required to obtain education, divided by the marginal utility of first-period consumption.

\section{Optimal Nonlinear Taxation with Commitment}

If the government can commit to its second-period tax policy, it cannot use skilltype information revealed in period 1 to implement lump-sum taxes in period 2, even though in period 2 it would be optimal to do so. Therefore, when the government can commit, it can be described as choosing lifetime tax treatments $\left\langle c_{L}^{1}, y_{L}^{1}, e_{L}, c_{L}^{2}, y_{L}^{2}\right\rangle$ and 
$\left\langle c_{H}^{1}, y_{H}^{1}, e_{H}, c_{H}^{2}, y_{H}^{2}\right\rangle$ for the low-skill and high-skill types, respectively, to maximise: ${ }^{7}$

$$
\begin{aligned}
& (1-\phi)\left[u\left(c_{L}^{1}\right)-v\left(\frac{y_{L}^{1}}{w_{L}^{1}}\right)-z\left(e_{L}\right)\right]+\phi\left[u\left(c_{H}^{1}\right)-v\left(\frac{y_{H}^{1}}{w_{H}^{1}}\right)-z\left(e_{H}\right)\right] \\
& +\delta(1-\phi)\left[u\left(c_{L}^{2}\right)-v\left(\frac{y_{L}^{2}}{w_{L}^{2}\left(e_{L}\right)}\right)\right]+\delta \phi\left[u\left(c_{H}^{2}\right)-v\left(\frac{y_{H}^{2}}{w_{H}^{2}\left(e_{H}\right)}\right)\right]
\end{aligned}
$$

subject to:

$$
\begin{gathered}
(1-\phi)\left[y_{L}^{1}-c_{L}^{1}-e_{L}\right]+\phi\left[y_{H}^{1}-c_{H}^{1}-e_{H}\right] \geq 0 \\
(1-\phi)\left[y_{L}^{2}-c_{L}^{2}\right]+\phi\left[y_{H}^{2}-c_{H}^{2}\right] \geq 0 \\
u\left(c_{H}^{1}\right)-v\left(\frac{y_{H}^{1}}{w_{H}^{1}}\right)-z\left(e_{H}\right)+\delta\left[u\left(c_{H}^{2}\right)-v\left(\frac{y_{H}^{2}}{w_{H}^{2}\left(e_{H}\right)}\right)\right] \geq \\
u\left(c_{L}^{1}\right)-v\left(\frac{y_{L}^{1}}{w_{H}^{1}}\right)-z\left(e_{L}\right)+\delta\left[u\left(c_{L}^{2}\right)-v\left(\frac{y_{L}^{2}}{\widehat{w}_{H}^{2}\left(e_{L}\right)}\right)\right]
\end{gathered}
$$

where the objective function (4.1) is a utilitarian social welfare function, (4.2) and (4.3) are the government's first- and second-period budget constraints, ${ }^{8}$ and (4.4) is the highskill type's incentive-compatibility constraint. Following the standard practice, we assume that the government knows the distribution of skill types, but each individual's type is private information. The government must therefore satisfy incentive-compatibility constraints to ensure that each individual chooses their intended tax treatment, rather than mimicking the other type by choosing the other type's tax treatment. However, we omit the low-skill type's incentive-compatibility constraint, as we focus on what Stiglitz [1982] calls the "normal" case and what Guesnerie [1995] calls "redistributive equilibria". That is, we assume that the parameters of the model are such that the government will be using its taxation powers to redistribute from high-skill to low-skill individuals, which creates an incentive for high-skill individuals to mimic low-skill individuals, but not vice versa. Accordingly, the high-skill type's incentive-compatibility constraint will bind at an optimum, whereas the low-skill type's incentive-compatibility constraint will

\footnotetext{
${ }^{7}$ While we do not observe such tax treatments in practice, it is well-known that the Revelation Principle implies that one can model the government as choosing each type's allocation directly subject to budget and incentive-compatibility constraints, rather than as specifying nonlinear tax schedules.

${ }^{8}$ As with the individuals, for simplicity we assume that the government cannot save or borrow.
} 
be slack. Finally, we use $\widehat{w}_{H}^{2}=w_{H}^{1}+\alpha e_{L}$ to denote a high-skill individual's second-period wage when mimicking.

It is shown in the Appendix that the solution to programme (4.1) - (4.4) yields:

Proposition 1 Optimal nonlinear taxation of income and education expenditures when the government can commit to its second-period tax policy has: $M T R I_{L}^{1}>0, M T R I_{H}^{1}=$ 0, $M T R I_{L}^{2}>0, M T R I_{H}^{2}=0, M T R E_{L}<0$, and $M T R E_{H}=0$.

The findings that it is optimal for low-skill individuals to face positive marginal income tax rates in both periods, and for high-skill individuals to face zero marginal income tax rates in both periods, are nothing but the standard "no-distortion-at-the-top" and "downward-distortion-at-the-bottom" results that typify static nonlinear income tax models. Likewise, the finding that the optimal marginal tax rate applicable to education expenditures by high-skill individuals is zero is another example of the no-distortion-atthe-top result. However, it is optimal for low-skill individuals to face a negative marginal tax rate on their education expenditures. It follows that the optimal education policy is progressive in this setting. Since low-skill individuals have a lower wage than highskill individuals, the former must work longer to earn any given level of pre-tax income. This means that low-skill individuals work longer than a mimicking high-skill individual. Therefore, low-skill individuals benefit more from an increase in their second-period wage via more education than a mimicking high-skill individual. The government can therefore make low-skill individuals better-off by distorting their education levels upwards via a negative marginal tax rate, without unduly enticing high-skill individuals to mimic. Alternatively, one can interpret the result in a similar manner to the Atkinson and Stiglitz [1976], Mirrlees [1976], and Christiansen [1984] arguments for supplementing income taxation with commodity taxation. Since low-skill individuals work longer and benefit more from education than does a mimicking high-skill individual, one could say that education and labour are in some sense complements. Then by the arguments in the literature for subsidising commodities that are complements with labour, it follows that it is optimal to apply a negative marginal tax rate to the low-skill type's education expenditures. 


\section{Optimal Nonlinear Taxation without Commitment}

If the government cannot commit to its second-period tax policy, it will take advantage of skill-type information revealed in period 1 to implement the first-best personalised lump-sum taxes in period 2. In this case, the government's behaviour in period 2 can be described as follows. Choose tax treatments $\left\langle c_{L}^{2}, y_{L}^{2}\right\rangle$ and $\left\langle c_{H}^{2}, y_{H}^{2}\right\rangle$ for the low-skill and high-skill types, respectively, to maximise:

$$
(1-\phi)\left[u\left(c_{L}^{2}\right)-v\left(\frac{y_{L}^{2}}{w_{L}^{2}\left(e_{L}\right)}\right)\right]+\phi\left[u\left(c_{H}^{2}\right)-v\left(\frac{y_{H}^{2}}{w_{H}^{2}\left(e_{H}\right)}\right)\right]
$$

subject to:

$$
(1-\phi)\left[y_{L}^{2}-c_{L}^{2}\right]+\phi\left[y_{H}^{2}-c_{H}^{2}\right] \geq 0
$$

where (5.1) is second-period social welfare, and (5.2) is the government's second-period budget constraint. Since in period 2 the government knows each individual's type, lowskill individuals must accept $\left\langle c_{L}^{2}, y_{L}^{2}\right\rangle$ and high-skill individuals must accept $\left\langle c_{H}^{2}, y_{H}^{2}\right\rangle$, i.e., the tax treatments need not satisfy incentive-compatibility constraints. The solution to programme $(5.1)-(5.2)$ yields the functions $c_{L}^{2}\left(\phi, w_{L}^{2}\left(e_{L}\right), w_{H}^{2}\left(e_{H}\right)\right), y_{L}^{2}(\cdot), c_{H}^{2}(\cdot)$ and $y_{H}^{2}(\cdot)$. Substituting these functions into (5.1) yields the value function $W^{2}(\cdot)$.

All individuals know that if they reveal their type in period 1, the government will solve programme $(5.1)-(5.2)$ in period 2. The government's behaviour in period 1 can therefore be described as follows. Choose tax treatments $\left\langle c_{L}^{1}, y_{L}^{1}, e_{L}\right\rangle$ and $\left\langle c_{H}^{1}, y_{H}^{1}, e_{H}\right\rangle$ for the low-skill and high-skill types, respectively, to maximise:

$$
(1-\phi)\left[u\left(c_{L}^{1}\right)-v\left(\frac{y_{L}^{1}}{w_{L}^{1}}\right)-z\left(e_{L}\right)\right]+\phi\left[u\left(c_{H}^{1}\right)-v\left(\frac{y_{H}^{1}}{w_{H}^{1}}\right)-z\left(e_{H}\right)\right]+\delta W^{2}(\cdot)
$$

subject to:

$$
\begin{gathered}
(1-\phi)\left[y_{L}^{1}-c_{L}^{1}-e_{L}\right]+\phi\left[y_{H}^{1}-c_{H}^{1}-e_{H}\right] \geq 0 \\
u\left(c_{H}^{1}\right)-v\left(\frac{y_{H}^{1}}{w_{H}^{1}}\right)-z\left(e_{H}\right)+\delta\left[u\left(c_{H}^{2}(\cdot)\right)-v\left(\frac{y_{H}^{2}(\cdot)}{w_{H}^{2}\left(e_{H}\right)}\right)\right] \geq \\
u\left(c_{L}^{1}\right)-v\left(\frac{y_{L}^{1}}{w_{H}^{1}}\right)-z\left(e_{L}\right)+\delta\left[u\left(c_{L}^{2}(\cdot)\right)-v\left(\frac{y_{L}^{2}(\cdot)}{\widehat{w}_{H}^{2}\left(e_{L}\right)}\right)\right]
\end{gathered}
$$


where (5.3) is first-period social welfare plus the discounted value of second-period social welfare, (5.4) is the government's first-period budget constraint, and (5.5) is the highskill type's incentive-compatibility constraint. Since the levels of education undertaken in period 1 affect the level of social welfare attainable in period 2 , the government takes this into account when designing the first-period tax system. Therefore, the objective function (5.3) includes the second-period value function. As in the commitment case, we assume that the redistributive goals of the government imply that the high-skill type's incentive-compatibility constraint binds at an optimum, whereas the low-skill type's incentive-compatibility constraint is slack. ${ }^{9}$ In order for high-skill individuals to be willing to reveal their type, the utility they obtain from choosing $\left\langle c_{H}^{1}, y_{H}^{1}, e_{H}\right\rangle$ in period 1 and thus revealing their type, plus the utility they obtain from the first-best tax treatment $\left\langle c_{H}^{2}(\cdot), y_{H}^{2}(\cdot)\right\rangle$ they will face in period 2, must be greater than or equal to the utility they could obtain by pretending to be low skill. In particular, if a highskill individual pretends to be low skill by choosing $\left\langle c_{L}^{1}, y_{L}^{1}, e_{L}\right\rangle$ in period 1 , they will be treated as such by the government in period 2, i.e., they will receive the low-skill type's tax treatment $\left\langle c_{L}^{2}(\cdot), y_{L}^{2}(\cdot)\right\rangle$. Finally, note that the second-period tax treatments depend in part upon the levels of education undertaken in period 1.

It is shown in the Appendix that the solutions to programmes (5.1) - (5.2) and (5.3) - (5.5) together imply:

Proposition 2 Optimal nonlinear taxation of income and education expenditures when the government cannot commit to its second-period tax policy has: $M T R I_{L}^{1}>0, M T R I_{H}^{1}=$ $0, M T R I_{L}^{2}=0, M T R I_{H}^{2}=0, M T R E_{L}<0$, and $M T R E_{H}>0$.

As in the commitment case, in period 1 the standard pattern of optimal marginal income tax rates applies. Both types face zero marginal income tax rates in period 2 simply because first-best taxation is used in that period. Low-skill individuals continue to face a negative marginal tax rate on their education expenditures, but that for high-skill individuals is now positive. First-best taxation in period 2 involves both types receiving

\footnotetext{
${ }^{9}$ Indeed, since high-skill individuals know that they will face first-best taxation in the second period if they reveal their type in the first period, their incentive to mimic low-skill individuals is stronger than when the government can commit.
} 
the same level of consumption, but high-skill individuals are required to work longer. ${ }^{10}$ Therefore, given that both types have the same preferences, high-skill individuals obtain less utility than low-skill individuals in period 2. Indeed, individual utility is generally decreasing in the wage rate under first-best taxation, since everyone receives the same level of consumption but higher-wage individuals must work longer. By imposing a positive marginal tax rate on education expenditures by high-skill individuals, the government is distorting their education and second-period wage downwards, but in fact raising their second-period utility. Concurrently, this reduces the gap between low-skill and high-skill wages, and reduces the low-skill type's second-period utility. The increase in the highskill type's second-period utility and decrease in the low-skill type's second-period utility make mimicking by high-skill individuals less attractive. Accordingly, the end result of imposing a positive marginal tax rate on the high-skill type's education expenditures is an increase in social welfare, obtained by relaxing the incentive-compatibility constraint.

Low-skill individuals face a negative marginal tax rate on their education expenditures for the same reason as when the government can commit, but now there is an additional factor at work. Imposing a negative marginal tax rate on education expenditures by low-skill individuals distorts their education and second-period wage upwards. By an analogous argument made above for the positive marginal tax rate on the high-skill type's education expenditures, a negative marginal tax rate on education expenditures by low-skill individuals decreases their utility under first-best taxation in period 2 , and increases that for high-skill individuals. This again makes mimicking less attractive, and increases social welfare by relaxing the incentive-compatibility constraint. Overall, the optimal education policy is progressive in this setting as well.

\section{Final Remarks}

This paper has analysed a simple two-period model in which the government may impose nonlinear taxes on both labour income and education expenditures. Given that our

\footnotetext{
${ }^{10}$ This has led some to describe first-best income taxation as Marxist in nature, because it takes from each individual according to their ability and gives to each individual according to their need.
} 
model is dynamic, we have considered the possibilities that the government may or may not be able to commit to its future tax policy. However, in both cases, our main conclusion is that optimal taxation of education expenditures is progressive.

For simplicity, we have assumed that second-period wages are a linear function of education, $w_{i}^{2}=w_{i}^{1}+\alpha e_{i}$, because for the reasons discussed earlier there does not seem to be any a priori reason to assume that $\partial w_{i}^{2}(\cdot) / \partial e_{i}$ is greater for one type of individual than the other. That said, one may wonder how our results change if a more general wage function, $w_{i}^{2}=w_{i}^{2}\left(w_{i}^{1}, e_{i}\right)$, is assumed. As it turns out, assuming a general wage function has no effect on our results regarding the optimal marginal tax rates applicable to the high-skill type's education expenditures. That is, they still face a zero marginal tax rate when the government can commit, and a positive marginal tax rate when the government cannot commit. Our results that the low-skill type should face a negative marginal tax rate on their education expenditures when the government can and cannot commit are also unaffected provided that $\partial w_{L}^{2}(\cdot) / \partial e_{L} \geq \partial \widehat{w}_{H}^{2}(\cdot) / \partial e_{L}$, but otherwise they cannot be signed. This is because if $\partial w_{L}^{2}(\cdot) / \partial e_{L}<\partial \widehat{w}_{H}^{2}(\cdot) / \partial e_{L}$, our argument that low-skill individuals benefit more from additional education than a mimicking high-skill individual may no longer be valid.

We have also assumed that $w_{H}^{2}>w_{L}^{2}$ for all relevant levels of education, which rules out the possibility of skill reversals. Allowing low-skill individuals to become high skill through investments in education would significantly complicate the analysis, because it would no longer be clear as to which type's incentive-compatibility constraint binds. Nevertheless, skill reversals are a real-world possibility, and therefore present an interesting avenue for future research.

\section{Appendix}

\section{Derivation of Equations (3.4) and (3.5)}

The relevant first-order conditions corresponding to programme (3.1) - (3.3) can be written as:

$$
u^{\prime}\left(c_{i}^{1}\right)-\lambda_{i}^{1}=0
$$




$$
\begin{gathered}
-v^{\prime}\left(l_{i}^{1}\right)+\lambda_{i}^{1} w_{i}^{1}\left[1-\frac{\partial T^{1}(\cdot)}{\partial y_{i}^{1}}\right]=0 \\
-z^{\prime}\left(e_{i}\right)-\lambda_{i}^{1}\left[1+\frac{\partial \tau(\cdot)}{\partial e_{i}}\right]+\lambda_{i}^{2} \alpha l_{i}^{2}\left[1-\frac{\partial T^{2}(\cdot)}{\partial y_{i}^{2}}\right]=0 \\
\delta u^{\prime}\left(c_{i}^{2}\right)-\lambda_{i}^{2}=0 \\
-\delta v^{\prime}\left(l_{i}^{2}\right)+\lambda_{i}^{2} w_{i}^{2}\left[1-\frac{\partial T^{2}(\cdot)}{\partial y_{i}^{2}}\right]=0
\end{gathered}
$$

where $\lambda_{i}^{1} \geq 0$ and $\lambda_{i}^{2} \geq 0$ are the multipliers on individual $i$ 's budget constraints (3.2) and (3.3), respectively. Straightforward manipulation of equations (A.1) and (A.2), and of (A.4) and (A.5), yields equation (3.4). Likewise, substituting (A.5) into (A.3), and combining the result with (A.1), yields equation (3.5).

\section{Proof of Proposition 1}

The relevant first-order conditions corresponding to programme (4.1) - (4.4) can be written as:

$$
\begin{gathered}
\left(1-\phi-\theta_{H}\right) u^{\prime}\left(c_{L}^{1}\right)-\lambda^{1}(1-\phi)=0 \\
-(1-\phi) v^{\prime}\left(\frac{y_{L}^{1}}{w_{L}^{1}}\right) \frac{1}{w_{L}^{1}}+\lambda^{1}(1-\phi)+\theta_{H} v^{\prime}\left(\frac{y_{L}^{1}}{w_{H}^{1}}\right) \frac{1}{w_{H}^{1}}=0 \\
-\left(1-\phi-\theta_{H}\right) z^{\prime}\left(e_{L}\right)-\lambda^{1}(1-\phi)+\frac{\delta(1-\phi) \alpha y_{L}^{2}}{w_{L}^{2}\left(e_{L}\right) w_{L}^{2}\left(e_{L}\right)} v^{\prime}\left(\frac{y_{L}^{2}}{w_{L}^{2}\left(e_{L}\right)}\right)-\frac{\delta \theta_{H} \alpha y_{L}^{2}}{\widehat{w}_{H}^{2}\left(e_{L}\right) \widehat{w}_{H}^{2}\left(e_{L}\right)} v^{\prime}\left(\frac{y_{L}^{2}}{\widehat{w}_{H}^{2}\left(e_{L}\right)}\right)=0 \\
\left(\phi+\theta_{H}\right) u^{\prime}\left(c_{H}^{1}\right)-\lambda^{1} \phi=0 \\
-\left(\phi+\theta_{H}\right) v^{\prime}\left(\frac{y_{H}^{1}}{w_{H}^{1}}\right) \frac{1}{w_{H}^{1}}+\lambda^{1} \phi=0 \\
-\left(\phi+\theta_{H}\right) z^{\prime}\left(e_{H}\right)-\lambda^{1} \phi+\frac{\delta\left(\phi+\theta_{H}\right) \alpha y_{H}^{2}}{w_{H}^{2}\left(e_{H}\right) w_{H}^{2}\left(e_{H}\right)} v^{\prime}\left(\frac{y_{H}^{2}}{w_{H}^{2}\left(e_{H}\right)}\right)=0 \\
\delta\left(1-\phi-\theta_{H}\right) u^{\prime}\left(c_{L}^{2}\right)-\lambda^{2}(1-\phi)=0 \\
-\delta(1-\phi) v^{\prime}\left(\frac{y_{L}^{2}}{w_{L}^{2}\left(e_{L}\right)}\right) \frac{1}{w_{L}^{2}\left(e_{L}\right)}+\lambda^{2}(1-\phi)+\delta \theta_{H} v^{\prime}\left(\frac{y_{L}^{2}}{\widehat{w}_{H}^{2}\left(e_{L}\right)}\right) \frac{1}{\widehat{w}_{H}^{2}\left(e_{L}\right)}=0 \\
\delta\left(\phi+\theta_{H}\right) u^{\prime}\left(c_{H}^{2}\right)-\lambda^{2} \phi=0 \\
-\delta\left(\phi+\theta_{H}\right) v^{\prime}\left(\frac{y_{H}^{2}}{w_{H}^{2}\left(e_{H}\right)}\right) \frac{1}{w_{H}^{2}\left(e_{H}\right)}+\lambda^{2} \phi=0
\end{gathered}
$$


where $\lambda^{1} \geq 0$ and $\lambda^{2} \geq 0$ are the multipliers on the first- and second-period budget constraints (4.2) and (4.3), respectively, while $\theta_{H} \geq 0$ is the multiplier on the high-skill type's incentive-compatibility constraint (4.4).

Using (A.6) and (A.7), we obtain:

$$
\left(1-\phi-\theta_{H}\right) u^{\prime}\left(c_{L}^{1}\right)=(1-\phi) v^{\prime}\left(\frac{y_{L}^{1}}{w_{L}^{1}}\right) \frac{1}{w_{L}^{1}}-\theta_{H} v^{\prime}\left(\frac{y_{L}^{1}}{w_{H}^{1}}\right) \frac{1}{w_{H}^{1}}
$$

Since $w_{H}^{1}>w_{L}^{1}$ and $v(\cdot)$ is strictly convex:

$$
(1-\phi) v^{\prime}\left(\frac{y_{L}^{1}}{w_{L}^{1}}\right) \frac{1}{w_{L}^{1}}-\theta_{H} v^{\prime}\left(\frac{y_{L}^{1}}{w_{H}^{1}}\right) \frac{1}{w_{H}^{1}}>(1-\phi) v^{\prime}\left(\frac{y_{L}^{1}}{w_{L}^{1}}\right) \frac{1}{w_{L}^{1}}-\theta_{H} v^{\prime}\left(\frac{y_{L}^{1}}{w_{L}^{1}}\right) \frac{1}{w_{L}^{1}}
$$

Therefore, (A.16) and (A.17) imply that:

$$
\left(1-\phi-\theta_{H}\right) u^{\prime}\left(c_{L}^{1}\right)>\left(1-\phi-\theta_{H}\right) v^{\prime}\left(\frac{y_{L}^{1}}{w_{L}^{1}}\right) \frac{1}{w_{L}^{1}}
$$

Equations (A.6) and (A.9) imply that $1-\phi-\theta_{H}>0$. Hence, (A.18) can be rearranged to yield:

$$
1>\frac{v^{\prime}\left(l_{L}^{1}\right)}{u^{\prime}\left(c_{L}^{1}\right) w_{L}^{1}}
$$

which using (3.4) establishes that $M T R I_{L}^{1}>0$. Analogous manipulations of equations (A.12) and (A.13) establish that $M T R I_{L}^{2}>0$.

Dividing (A.10) by (A.9) and rearranging yields:

$$
\frac{v^{\prime}\left(l_{H}^{1}\right)}{u^{\prime}\left(c_{H}^{1}\right) w_{H}^{1}}=1
$$

which using (3.4) establishes that $M T R I_{H}^{1}=0$. Analogous manipulations of equations (A.14) and (A.15) establish that $M T R I_{H}^{2}=0$.

Equations (A.6) and (A.8) can be combined to yield:

$$
\left(1-\phi-\theta_{H}\right) \frac{\alpha \delta l_{L}^{2} v^{\prime}\left(l_{L}^{2}\right)}{w_{L}^{2}\left(e_{L}\right)}-\left(1-\phi-\theta_{H}\right) z^{\prime}\left(e_{L}\right)-\left(1-\phi-\theta_{H}\right) u^{\prime}\left(c_{L}^{1}\right)
$$




$$
=\delta \theta_{H} \alpha y_{L}^{2}\left[\frac{v^{\prime}\left(\frac{y_{L}^{2}}{\widehat{w}_{H}^{2}\left(e_{L}\right)}\right)}{\widehat{w}_{H}^{2}\left(e_{L}\right) \widehat{w}_{H}^{2}\left(e_{L}\right)}-\frac{v^{\prime}\left(\frac{y_{L}^{2}}{w_{L}^{2}\left(e_{L}\right)}\right)}{w_{L}^{2}\left(e_{L}\right) w_{L}^{2}\left(e_{L}\right)}\right]
$$

Dividing both sides of (A.21) by $\left(1-\phi-\theta_{H}\right) u^{\prime}\left(c_{L}^{1}\right)$ and using (3.5), we obtain:

$$
\operatorname{MTRE}_{L}=\frac{\delta \theta_{H} \alpha y_{L}^{2}}{\left(1-\phi-\theta_{H}\right) u^{\prime}\left(c_{L}^{1}\right)}\left[\frac{v^{\prime}\left(\frac{y_{L}^{2}}{\widehat{w}_{H}^{2}\left(e_{L}\right)}\right)}{\widehat{w}_{H}^{2}\left(e_{L}\right) \widehat{w}_{H}^{2}\left(e_{L}\right)}-\frac{v^{\prime}\left(\frac{y_{L}^{2}}{w_{L}^{2}\left(e_{L}\right)}\right)}{w_{L}^{2}\left(e_{L}\right) w_{L}^{2}\left(e_{L}\right)}\right]
$$

Since $\widehat{w}_{H}^{2}\left(e_{L}\right)>w_{L}^{2}\left(e_{L}\right)$ and $v(\cdot)$ is strictly convex, the term in square brackets in (A.22) is negative. Hence $M T R E_{L}<0$.

Equations (A.9) and (A.11) can be combined to yield:

$$
\left(\phi+\theta_{H}\right) \frac{\alpha \delta l_{H}^{2} v^{\prime}\left(l_{H}^{2}\right)}{w_{H}^{2}\left(e_{H}\right)}-\left(\phi+\theta_{H}\right) z^{\prime}\left(e_{H}\right)-\left(\phi+\theta_{H}\right) u^{\prime}\left(c_{H}^{1}\right)=0
$$

Dividing (A.23) by $\left(\phi+\theta_{H}\right) u^{\prime}\left(c_{H}^{1}\right)$ and using (3.5) establishes that $M T R E_{H}=0$.

\section{Proof of Proposition 2}

The first-order conditions corresponding to programme (5.1) - (5.2) are:

$$
\begin{gathered}
(1-\phi) u^{\prime}\left(c_{L}^{2}\right)-\lambda^{2}(1-\phi)=0 \\
-(1-\phi) v^{\prime}\left(\frac{y_{L}^{2}}{w_{L}^{2}\left(e_{L}\right)}\right) \frac{1}{w_{L}^{2}\left(e_{L}\right)}+\lambda^{2}(1-\phi)=0 \\
\phi u^{\prime}\left(c_{H}^{2}\right)-\lambda^{2} \phi=0 \\
-\phi v^{\prime}\left(\frac{y_{H}^{2}}{w_{H}^{2}\left(e_{H}\right)}\right) \frac{1}{w_{H}^{2}\left(e_{H}\right)}+\lambda^{2} \phi=0 \\
(1-\phi)\left[y_{L}^{2}-c_{L}^{2}\right]+\phi\left[y_{H}^{2}-c_{H}^{2}\right]=0
\end{gathered}
$$

where $\lambda^{2} \geq 0$ is the multiplier on the second-period budget constraint (5.2).

Dividing (A.25) by (A.24) and rearranging yields:

$$
\frac{v^{\prime}\left(l_{L}^{2}\right)}{u^{\prime}\left(c_{L}^{2}\right) w_{L}^{2}\left(e_{L}\right)}=1
$$


while dividing (A.27) by (A.26) and rearranging yields:

$$
\frac{v^{\prime}\left(l_{H}^{2}\right)}{u^{\prime}\left(c_{H}^{2}\right) w_{H}^{2}\left(e_{H}\right)}=1
$$

which using (3.4) establishes that $M T R I_{L}^{2}=0$ and $M T R I_{H}^{2}=0$.

The relevant first-order conditions corresponding to programme (5.3) - (5.5) can be written as:

$$
\begin{aligned}
& \left(1-\phi-\theta_{H}\right) u^{\prime}\left(c_{L}^{1}\right)-\lambda^{1}(1-\phi)=0 \\
& -(1-\phi) v^{\prime}\left(\frac{y_{L}^{1}}{w_{L}^{1}}\right) \frac{1}{w_{L}^{1}}+\lambda^{1}(1-\phi)+\theta_{H} v^{\prime}\left(\frac{y_{L}^{1}}{w_{H}^{1}}\right) \frac{1}{w_{H}^{1}}=0 \\
& -\left(1-\phi-\theta_{H}\right) z^{\prime}\left(e_{L}\right)-\lambda^{1}(1-\phi)+\delta \frac{\partial W^{2}(\cdot)}{\partial e_{L}}-\frac{\delta \theta_{H} \alpha y_{L}^{2}}{\widehat{w}_{H}^{2}\left(e_{L}\right) \widehat{w}_{H}^{2}\left(e_{L}\right)} v^{\prime}\left(\frac{y_{L}^{2}}{\widehat{w}_{H}^{2}\left(e_{L}\right)}\right) \\
& +\delta \theta_{H}\left[u^{\prime}\left(c_{H}^{2}\right) \frac{\partial c_{H}^{2}(\cdot)}{\partial e_{L}}-\frac{v^{\prime}\left(\frac{y_{H}^{2}}{w_{H}^{2}\left(e_{H}\right)}\right)}{w_{H}^{2}\left(e_{H}\right)} \frac{\partial y_{H}^{2}(\cdot)}{\partial e_{L}}-u^{\prime}\left(c_{L}^{2}\right) \frac{\partial c_{L}^{2}(\cdot)}{\partial e_{L}}+\frac{v^{\prime}\left(\frac{y_{L}^{2}}{\widehat{w}_{H}^{2}\left(e_{L}\right)}\right)}{\widehat{w}_{H}^{2}\left(e_{L}\right)} \frac{\partial y_{L}^{2}(\cdot)}{\partial e_{L}}\right]=0 \\
& \left(\phi+\theta_{H}\right) u^{\prime}\left(c_{H}^{1}\right)-\lambda^{1} \phi=0 \\
& -\left(\phi+\theta_{H}\right) v^{\prime}\left(\frac{y_{H}^{1}}{w_{H}^{1}}\right) \frac{1}{w_{H}^{1}}+\lambda^{1} \phi=0 \\
& -\left(\phi+\theta_{H}\right) z^{\prime}\left(e_{H}\right)-\lambda^{1} \phi+\delta \frac{\partial W^{2}(\cdot)}{\partial e_{H}}+\frac{\delta \theta_{H} \alpha y_{H}^{2}}{w_{H}^{2}\left(e_{H}\right) w_{H}^{2}\left(e_{H}\right)} v^{\prime}\left(\frac{y_{H}^{2}}{w_{H}^{2}\left(e_{H}\right)}\right) \\
& +\delta \theta_{H}\left[u^{\prime}\left(c_{H}^{2}\right) \frac{\partial c_{H}^{2}(\cdot)}{\partial e_{H}}-\frac{v^{\prime}\left(\frac{y_{H}^{2}}{w_{H}^{2}\left(e_{H}\right)}\right)}{w_{H}^{2}\left(e_{H}\right)} \frac{\partial y_{H}^{2}(\cdot)}{\partial e_{H}}-u^{\prime}\left(c_{L}^{2}\right) \frac{\partial c_{L}^{2}(\cdot)}{\partial e_{H}}+\frac{v^{\prime}\left(\frac{y_{L}^{2}}{\widehat{w}_{H}^{2}\left(e_{L}\right)}\right)}{\widehat{w}_{H}^{2}\left(e_{L}\right)} \frac{\partial y_{L}^{2}(\cdot)}{\partial e_{H}}\right]=0
\end{aligned}
$$

where $\lambda^{1} \geq 0$ is the multiplier on the first-period budget constraint (5.4), and $\theta_{H} \geq 0$ is the multiplier on the high-skill type's incentive-compatibility constraint (5.5).

Using (A.31) and (A.32) it can be shown that $M T R I_{L}^{1}>0$, and using (A.34) and (A.35) it can be shown that $M T R I_{H}^{1}=0$. The proofs of these results are analogous to those for the case when the government can commit, and are therefore omitted.

To derive expressions for $\partial W^{2}(\cdot) / \partial e_{L}$ and $\partial W^{2}(\cdot) / \partial e_{H}$, note that the Lagrangian 
corresponding to programme $(5.1)-(5.2)$ can be written as:

$\mathcal{L}=(1-\phi)\left[u\left(c_{L}^{2}\right)-v\left(\frac{y_{L}^{2}}{w_{L}^{2}\left(e_{L}\right)}\right)\right]+\phi\left[u\left(c_{H}^{2}\right)-v\left(\frac{y_{H}^{2}}{w_{H}^{2}\left(e_{H}\right)}\right)\right]+\lambda^{2}\left[(1-\phi)\left[y_{L}^{2}-c_{L}^{2}\right]+\phi\left[y_{H}^{2}-c_{H}^{2}\right]\right]$

By the Envelope Theorem:

$$
\begin{gathered}
\frac{\partial W^{2}(\cdot)}{\partial e_{L}}=\frac{\partial \mathcal{L}(\cdot)}{\partial e_{L}}=\frac{\alpha(1-\phi) y_{L}^{2}}{w_{L}^{2}\left(e_{L}\right) w_{L}^{2}\left(e_{L}\right)} v^{\prime}\left(\frac{y_{L}^{2}}{w_{L}^{2}\left(e_{L}\right)}\right) \\
\frac{\partial W^{2}(\cdot)}{\partial e_{H}}=\frac{\partial \mathcal{L}(\cdot)}{\partial e_{H}}=\frac{\alpha \phi y_{H}^{2}}{w_{H}^{2}\left(e_{H}\right) w_{H}^{2}\left(e_{H}\right)} v^{\prime}\left(\frac{y_{H}^{2}}{w_{H}^{2}\left(e_{H}\right)}\right)
\end{gathered}
$$

Substituting (A.38) into (A.33) and combining the result with (A.31) yields:

$$
\begin{gathered}
\left(1-\phi-\theta_{H}\right) \frac{\alpha \delta l_{L}^{2} v^{\prime}\left(l_{L}^{2}\right)}{w_{L}^{2}\left(e_{L}\right)}-\left(1-\phi-\theta_{H}\right) z^{\prime}\left(e_{L}\right)-\left(1-\phi-\theta_{H}\right) u^{\prime}\left(c_{L}^{1}\right) \\
=\delta \theta_{H} \alpha y_{L}^{2}\left[\frac{v^{\prime}\left(\frac{y_{L}^{2}}{\widehat{w}_{H}^{2}\left(e_{L}\right)}\right)}{\widehat{w}_{H}^{2}\left(e_{L}\right) \widehat{w}_{H}^{2}\left(e_{L}\right)}-\frac{v^{\prime}\left(\frac{y_{L}^{2}}{w_{L}^{2}\left(e_{L}\right)}\right)}{w_{L}^{2}\left(e_{L}\right) w_{L}^{2}\left(e_{L}\right)}\right]+\delta \theta_{H} u^{\prime}\left(c_{L}^{2}\right)\left[\frac{\partial c_{L}^{2}(\cdot)}{\partial e_{L}}-\frac{\partial c_{H}^{2}(\cdot)}{\partial e_{L}}\right] \\
+\delta \theta_{H}\left[\frac{v^{\prime}\left(\frac{y_{H}^{2}}{w_{H}^{2}\left(e_{H}\right)}\right)}{w_{H}^{2}\left(e_{H}\right)} \frac{\partial y_{H}^{2}(\cdot)}{\partial e_{L}}-\frac{v^{\prime}\left(\frac{y_{L}^{2}}{\widehat{w}_{H}^{2}\left(e_{L}\right)}\right)}{\widehat{w}_{H}^{2}\left(e_{L}\right)} \frac{\partial y_{L}^{2}(\cdot)}{\partial e_{L}}\right]
\end{gathered}
$$

where use has been made of $u^{\prime}\left(c_{L}^{2}\right)=u^{\prime}\left(c_{H}^{2}\right)$, which follows from (A.24) and (A.26). Dividing both sides of (A.40) by $\left(1-\phi-\theta_{H}\right) u^{\prime}\left(c_{L}^{1}\right)$ and using (3.5), we obtain:

$$
\begin{gathered}
M T R E_{L}=\frac{\delta \theta_{H} \alpha y_{L}^{2}}{\left(1-\phi-\theta_{H}\right) u^{\prime}\left(c_{L}^{1}\right)}\left[\frac{v^{\prime}\left(\frac{y_{L}^{2}}{\widehat{w}_{H}^{2}\left(e_{L}\right)}\right)}{\widehat{w}_{H}^{2}\left(e_{L}\right) \widehat{w}_{H}^{2}\left(e_{L}\right)}-\frac{v^{\prime}\left(\frac{y_{L}^{2}}{w_{L}^{2}\left(e_{L}\right)}\right)}{w_{L}^{2}\left(e_{L}\right) w_{L}^{2}\left(e_{L}\right)}\right] \\
+\frac{\delta \theta_{H} u^{\prime}\left(c_{L}^{2}\right)}{\left(1-\phi-\theta_{H}\right) u^{\prime}\left(c_{L}^{1}\right)}\left[\frac{\partial c_{L}^{2}(\cdot)}{\partial e_{L}}-\frac{\partial c_{H}^{2}(\cdot)}{\partial e_{L}}\right] \\
+\frac{\delta \theta_{H}}{\left(1-\phi-\theta_{H}\right) u^{\prime}\left(c_{L}^{1}\right)}\left[\frac{v^{\prime}\left(\frac{y_{H}^{2}}{w_{H}^{2}\left(e_{H}\right)}\right)}{w_{H}^{2}\left(e_{H}\right)} \frac{\partial y_{H}^{2}(\cdot)}{\partial e_{L}}-\frac{v^{\prime}\left(\frac{y_{L}^{2}}{\widehat{w}_{H}^{2}\left(e_{L}\right)}\right)}{\widehat{w}_{H}^{2}\left(e_{L}\right)} \frac{\partial y_{L}^{2}(\cdot)}{\partial e_{L}}\right]
\end{gathered}
$$

It follows from (A.31) and (A.34) that $1-\phi-\theta_{H}>0$. And since $\widehat{w}_{H}^{2}\left(e_{L}\right)>w_{L}^{2}\left(e_{L}\right)$ and $v(\cdot)$ is strictly convex, the first term in (A.41) is negative. By applying the Implicit 
Function Theorem and Cramer's Rule to (A.24) - (A.28), it can be shown that:

$$
\frac{\partial c_{L}^{2}(\cdot)}{\partial e_{L}}=\frac{\partial c_{H}^{2}(\cdot)}{\partial e_{L}}>0 \quad \frac{\partial y_{H}^{2}(\cdot)}{\partial e_{L}}<0 \quad \frac{\partial y_{L}^{2}(\cdot)}{\partial e_{L}}>0
$$

Therefore, the second term in (A.41) equals zero, while the third term is negative. This establishes that $M T R E_{L}<0$.

Substituting (A.39) into (A.36) and combining the result with (A.34) yields:

$$
\begin{gathered}
\left(\phi+\theta_{H}\right) \frac{\alpha \delta l_{H}^{2} v^{\prime}\left(l_{H}^{2}\right)}{w_{H}^{2}\left(e_{H}\right)}-\left(\phi+\theta_{H}\right) z^{\prime}\left(e_{H}\right)-\left(\phi+\theta_{H}\right) u^{\prime}\left(c_{H}^{1}\right) \\
=\delta \theta_{H} u^{\prime}\left(c_{H}^{2}\right)\left[\frac{\partial c_{L}^{2}(\cdot)}{\partial e_{H}}-\frac{\partial c_{H}^{2}(\cdot)}{\partial e_{H}}\right]+\delta \theta_{H}\left[\frac{v^{\prime}\left(\frac{y_{H}^{2}}{w_{H}^{2}\left(e_{H}\right)}\right)}{w_{H}^{2}\left(e_{H}\right)} \frac{\partial y_{H}^{2}(\cdot)}{\partial e_{H}}-\frac{v^{\prime}\left(\frac{y_{L}^{2}}{\widehat{w}_{H}^{2}\left(e_{L}\right)}\right)}{\widehat{w}_{H}^{2}\left(e_{L}\right)} \frac{\partial y_{L}^{2}(\cdot)}{\partial e_{H}}\right]
\end{gathered}
$$

where use has been made of the fact that $u^{\prime}\left(c_{L}^{2}\right)=u^{\prime}\left(c_{H}^{2}\right)$. Dividing both sides of (A.43) by $\left(\phi+\theta_{H}\right) u^{\prime}\left(c_{H}^{1}\right)$ and using (3.5), we obtain:

$$
\begin{gathered}
M T R E_{H}=\frac{\delta \theta_{H} u^{\prime}\left(c_{H}^{2}\right)}{\left(\phi+\theta_{H}\right) u^{\prime}\left(c_{H}^{1}\right)}\left[\frac{\partial c_{L}^{2}(\cdot)}{\partial e_{H}}-\frac{\partial c_{H}^{2}(\cdot)}{\partial e_{H}}\right] \\
+\frac{\delta \theta_{H}}{\left(\phi+\theta_{H}\right) u^{\prime}\left(c_{H}^{1}\right)}\left[\frac{v^{\prime}\left(\frac{y_{H}^{2}}{w_{H}^{2}\left(e_{H}\right)}\right)}{w_{H}^{2}\left(e_{H}\right)} \frac{\partial y_{H}^{2}(\cdot)}{\partial e_{H}}-\frac{v^{\prime}\left(\frac{y_{L}^{2}}{\widehat{w}_{H}^{2}\left(e_{L}\right)}\right)}{\widehat{w}_{H}^{2}\left(e_{L}\right)} \frac{\partial y_{L}^{2}(\cdot)}{\partial e_{H}}\right]
\end{gathered}
$$

By applying the Implicit Function Theorem and Cramer's Rule to (A.24) - (A.28), it can be shown that:

$$
\frac{\partial c_{L}^{2}(\cdot)}{\partial e_{H}}=\frac{\partial c_{H}^{2}(\cdot)}{\partial e_{H}}>0 \quad \frac{\partial y_{H}^{2}(\cdot)}{\partial e_{H}}>0 \quad \frac{\partial y_{L}^{2}(\cdot)}{\partial e_{H}}<0
$$

Therefore, the first term in (A.44) equals zero, while the second term is positive. This establishes that $M T R E_{H}>0$. 


\section{References}

[1] Andersson, F. and K. Konrad [2003], "Human Capital Investment and Globalization in Extortionary States", Journal of Public Economics, 87, 1539-1555.

[2] Apps, P. and R. Rees [2006], "Repeated Optimal Nonlinear Income Taxation", mimeo.

[3] Atkinson, A. and J. Stiglitz [1976], "The Design of Tax Structure: Direct Versus Indirect Taxation", Journal of Public Economics, 6, 55-75.

[4] Blumkin, T. and E. Sadka [2008], "A Case for Taxing Education", International Tax and Public Finance, 15, 145-163.

[5] Boadway, R., N. Marceau and M. Marchand [1996], "Investment in Education and the Time Inconsistency of Redistributive Tax Policy", Economica, 63, 171-189.

[6] Bovenberg, A. and B. Jacobs [2005], "Redistribution and Education Subsidies are Siamese Twins", Journal of Public Economics, 89, 2005-2035.

[7] Brett, C. and J. Weymark [2003], "Financing Education Using Optimal Redistributive Taxation", Journal of Public Economics, 87, 2549-2569.

[8] Brett, C. and J. Weymark [2008], "Optimal Nonlinear Taxation of Income and Savings without Commitment", Vanderbilt University Working Paper, No. 08-W05.

[9] Christiansen, V [1984], "Which Commodity Taxes Should Supplement the Income Tax?", Journal of Public Economics, 24, 195-220.

[10] De Fraja, G [2002], "The Design of Optimal Education Policies", Review of Economic Studies, 69, 437-466.

[11] Fleurbaey, M., R. Gary-Bobo and D. Maguain [2002], "Education, Distributive Justice, and Adverse Selection", Journal of Public Economics, 84, 113-150.

[12] Gaube, T [2007], "Optimum Taxation of Each Year's Income", Journal of Public Economic Theory, 9, 127-150.

[13] Golosov, M., M. Troshkin and A. Tsyvinski [2010], "Optimal Taxation: Merging Micro and Macro Approaches", mimeo.

[14] Golosov, M., A. Tsyvinski and I. Werning [2006], "New Dynamic Public Finance: A User's Guide", NBER Macroeconomics Annual, 2006, 317-387.

[15] Grout, P [1983], "Imperfect Information, Markets and Public Provision of Education", Journal of Public Economics, 22, 113-121.

[16] Guesnerie, R [1995], A Contribution to the Pure Theory of Taxation, Cambridge University Press. 
[17] Guo, J-T. and A. Krause [2010], "Optimal Nonlinear Income Taxation with Habit Formation", Journal of Public Economic Theory, forthcoming.

[18] Hare, P. and D. Ulph [1979], "On Education and Distribution", Journal of Political Economy, 87, S193-S212.

[19] Kocherlakota, N [2010], The New Dynamic Public Finance, Princeton University Press.

[20] Krause, A [2006], "Redistributive Taxation and Public Education", Journal of Public Economic Theory, 8, 807-819.

[21] Krause, A [2009a], "Education and Taxation Policies in the Presence of Countervailing Incentives", Economica, 76, 387-399.

[22] Krause, A [2009b], "Optimal Nonlinear Income Taxation with Learning-by-Doing", Journal of Public Economics, 93, 1098-1110.

[23] Maldonado, D [2008], "Education Policies and Optimal Taxation", International Tax and Public Finance, 15, 131-143.

[24] Mirrlees, J [1971], "An Exploration in the Theory of Optimum Income Taxation", Review of Economic Studies, 38, 175-208.

[25] Mirrlees, J [1976], "Optimal Tax Theory: A Synthesis", Journal of Public Economics, 6, 327-358.

[26] Stiglitz, J [1982], "Self-selection and Pareto Efficient Taxation", Journal of Public Economics, 17, 213-240.

[27] Tuomala, M [1986], "On the Optimal Income Taxation and Educational Decisions", Journal of Public Economics, 30, 183-198.

[28] Ulph, D [1977], "On the Optimal Distribution of Income and Educational Expenditure", Journal of Public Economics, 8, 341-356. 